\title{
Unique Identity / Unique Human Identity / Unique World Identity / Unique Citizen Identity / Human Identity / Citizen Identity - Number
}

\author{
Ziaur Rahman \\ Software Engineer, Bangladesh
}

\begin{abstract}
Unique Identity for every human and non-human entity on the earth is the crucial issue for the time being. Unique Identity means assigning numeric identity number to every human aged greater or equal to 0 day, each shop/institute/organization/farm/company and other like entities within countries and international organizations/bodies from now/floating date. It is envisaged for peace and security of the mankind, simplifying complicated public systems within country and in the international arena, to expedite building global village and increasing cultural, economic/business relation and amity with trust among people beyond the border. This will bring discipline in human life in the world. It will substantially reduce militancy and other minor or major criminal incidents. In this system I recommend to keep an entity profile against each entity of the country in a government database. And this will facilitate people home and abroad manifold.
\end{abstract}

Keywords: Account security, citizen identity, citizen safety, human identity, information security, internet security, public discipline, public security, safe communication, security, security rules, security system, unique citizen identity, unique human identity, unique identity, unique identity number, unique people identity, unique world identity.

\section{Introduction}

We, peoples in the world are reeling under security threats like snatching, smuggling, stealing, piracy, account hack, web-site hack, eavesdropping, money misappropriation, pilferage, money laundering, illegal VOIP, SIM/RIM cloning, human trafficking, house/bank robbery/theft, militancy, terrorism etc. Present system of Social Security Number or Citizen IDentity could not give expected solution to this security problems. No invention, government policy, international security policy could not work as expectation. Anti-spyware software, anti-virus software, ethical hacker, ICT Police, tech-intelligence nothing could protect peoples. At present we use National IDentity card, Smart IDentity card, SIM/RIM for mobile connection, electronic handset, Database and Datacenters. Using only these resources applying my 'Unique IDentity' research paper in a new strategy with government and international administrative reformed rule we could get a 95\% secure world. In this paper I depict all technical and administrative tactics of this new system.

\section{Definition}

\section{The System}

Every human on the earth will have a Human IDentity number (HID). This HID number will be unique in the world which will be formed with respective Country Information and Communication ID (CICID) (that is now said as 'Country Code' in case of international dialing) followed by unique Citizen IDentity (CID) number in the country.

Similarly each in entity a country like institute/organization/shop/industry/farm/company/bank/insurance/cooperative/enterprise will be assigned a unique Identity number too.

United Nations will hold Information and Communication ID number for itself in country code serial. This could be 000 .

World Information and Communication Union (WICU) will keep some ID numbers for international organizations, multinational commercial companies, international bodies or institutes in United Nations serial.

\section{Infrastructure}

International Telecommunication Union (ITU), an organ of United Nations to be reformed as World Information and Communication Union (WICU) and it will remain under United Nations. It will control worldwide information and communication affairs among countries. It will hold some data centers and infrastructures to be used to maintain world-wide communication and to resolve conflict between/among countries. There will have only one information and communication channel within each country and in international arena. The only channel/medium for information and communication is the internet in the world. Through internet phone- 
call/voice-chat, video-chat, message/email, file/document transfer, radio/television live streaming anything will be done. There will have no hardware/software for NFC(Near Field Communication), Bluetooth, intercom, short distance wireless/cable device connection, telephone/radio/television tower/base station, dish antenna - these are all would be banned (this rule could be relaxed for research labs, defense services and other exceptional entities).

\section{Systems}

The HID will be a person's mobile phone number, email address, finance/bank account number, land/vehicle/other property owner id, insurance number, web address, investor ID, member id in any organization/cooperative, Facebook/twitter id, in a word, it is his tether to the world.

Each place(less/equal one square kilometer) in the world will have a name/code which will be used to detect the place through internet / Global Positioning System (GPS) / other systems. If needs, to be able to track location of an entity it will help us. In this respect we could make it mandatory for mobile communication device manufacturer to install location tracking device without alternative option in hardware/software in all communication machines/devices and we could set an international standard for this.

With this HID the entity's profile will be stored in his country citizen database. This information will be accessible by all concerned authorities in country as well as international bodies. If the person obtains international port/border passing permission by his country Govt., it will be written in his profile info book by authorized Govt. office. In his profile book, his crime and sentence report will be embedded too. This citizen database will also be stored/updated in two more datacenters in different places in different file format for safety. In case of international communication, each communication info will be stored/updated in two different level databases in different places in different formats by WICU. This profile would be then his official deed. But specific office would get access right to assigned page/s only as fixed by his country authority in the profile book. So he need not carry hard passport, identity card, driving license card etc.

\section{Assigning ID\#}

National ID (CID) of a man: 9992824539090(suppose).

His HID and phone/mobile \# is 8809992824539090. Here, 880 is Country Information and Communication ID (CICID) of a certain country. If there are network connection of more than one provider company, then his phone/mobile \# is 880999282453909017 or 880999282453909015 and so on. Here, $17 / 15$ are last two digits of Operator ID in that country. And the HID/phone/mobile\# will be his only email address, personal web address, Facebook/Twitter id, investor ID, member id in any organization/cooperative etc. ID numbers from 4,010,835,010,149 to 9,999,999,999,999 will be allocated for citizen identity number assigning in a country.

For ID number for shops numbers from 4,005,835,010,149 to 4,010,835,010,149 will be assigned. Country Code will precede the shop ID number. Then the ID\# will be as 8804005996783432 .

For ID number for company/enterprises numbers from 4,004,335,010,149 to 4,005,835,010,149 will be assigned. Country Code will precede the company ID number. Then the ID\# will be as 8804004362784350 .

For ID number for farms numbers from 3,999,335,010,149 to 4,004,335,010,149 will be assigned. Country Code will precede the farm ID number. Then the ID\# will be as 8804000398227843 .

For ID number for education institutions numbers from 3,997,835,010,149 to 3,999,335,010,149 will be assigned. Country Code will precede the institute ID number. Then the ID\# will be as 8803998595679998 .

For ID number for factories numbers from 3,997,735,010,149 to 3,997,835,010,149 will be assigned. Country Code will precede the factory ID number. Then the ID\# will be as 8803997831969997 .

For ID number for banks numbers from 3,997,725,010,149 to 3,997,735,010,149 will be assigned. Country Code will precede the bank ID number. Then the ID\# will be as 8803997730969997.

For ID number for insurances numbers from 3,997,715,010,149 to 3,997,725,010,149 will be assigned. Country Code will precede the insurance ID number. Then the ID\# will be as 8803997723959929 .

Bank/insurance account \# of a citizen: Account number will be composed as the citizen's phone number followed by serial number of accounts of the citizen in that bank/insurance followed by last four digits of the bank's/insurance's ID\#. This account \# would be like 880999282453909019997.

For ID number for cooperatives numbers from 3,997,665,010,149 to $3,997,715,010,149$ will be assigned. Country Code will precede the cooperative ID number. Then the ID\# will be as 8803997711699976 .

For ID number for organizations numbers from 3,997,635,010,149 to 3,997,665,010,149 will be assigned. Country Code will precede the organization ID number. Then the ID\# will be as 8803997645959943 .

For ID number for industries numbers from 3,997,615,010,149 to 3,997,635,010,149 will be assigned. Country Code will precede the industry ID number. Then the ID\# will be as 8803997634629956 . 
For ID number for forces numbers from 3,997,614,010,149 to 3,997,615,010,149 will be assigned. Country Code will precede the force ID number. Then the ID\# will be as 8803997615009134 .

For ID number for parliament numbers from 3,997,614,010,099 to 3,997,614,010,149 will be assigned. Country Code will precede the parliament ID number. Then the ID\# will be as 8803997614010100 .

For ID number for secretariats numbers from 3,997,613,910,099 to 3,997,614,010,099 will be assigned. Country Code will precede the secretariat ID number. Then the ID\# will be as 8803997613998979 .

For ID number for ministries numbers from 3,997,613,900,099 to 3,997,613,910,099 will be assigned. Country Code will precede the ministry ID number. Then the ID\# will be as 8803997613909349 .

For ID number for prime ministry numbers from 3,997,613,899,999 to $3,997,613,900,099$ will be assigned. Country Code will precede the prime ministry ID number. Then the ID\# will be as 8803997613900050.

For ID number for presidency numbers from 3,997,613,899,949 to 3,997,613,899,999 will be assigned. Country Code will precede the presidency ID number. Then the ID\# will be as 8803997613899953 .

ID number for vehicles: There will have Vehicle Category Code. Vehicle Id\# will be like 8809992824539090674 . Here first sixteen digits number is vehicle owner's HID number followed by two digits Vehicle Category Code followed by serial number of the vehicle in same category owned by him.

\section{Anomaly Punishment}

If anybody commits anomaly/irregularity/crime using Information and Communication Channel for first crime he/she will be tried under usual criminal code, where fine will be credited from his account to national exchequer directly. For second crime, punishment is as before (As warning his ID could be suspended for 10 days). If anybody commits anomaly for third time, he/she will be punished as first anomaly as well as his/her Information and Communication ID number will be terminated forever.

\section{Advantages}

This system will provide us tremendous strength to trace entity/criminal. It will help us to fight menace of rebellion, hacking, piracy, snatching, corruption, irregularities and communication/ internet related all crimes. States in the world may get rid of militancy and revolt. It will reduce hassles and complexity of legal procedures in public life. Aftermath we could get a more peaceful world.

\section{Logical Steps}

United Nations (UN) to call world convention to fix following things:

1. Country Information and Communication ID (CICID).

2. Time-frame to accomplish assignment of Citizen IDentity Number (CID) in the countries and Human Identity Number (HID).

3. Time-frame to setup internal Data-Centers in the countries.

4. Reforming http, ftp, WWW and other information and communication protocols for secure adoption of new system in country as well as internationally.

5. To fix and setup in-country information and communicational infrastructure and regulations reforming deadline.

6. A time-line and strategy for making entity profile databases in each country.

\section{Conclusion}

In current course of time, it needs an upgradation of administrative structure. Otherwise state can't keep up with the will of the people. The Unique Identity system is such an upgrading model. This system will establish equal rights of every non-human and human entity in the state and internationally. The goal of this system is security, peace and easy communication system. It will bring highest discipline among the entities. It will make daily life more comfortable and easy. It would also contribute to the human rights maintaining. I expect, it will expedite peace and economic growth throughout the world. 